\title{
EL DISCURSO POLÍTICO EN LA VENEZUELA DE HUGO CHÁVEZ: DE LA REFORMA CONSTITUCIONAL A LA ENMIENDA (2007-2009)
}

\author{
THE POLITICAL DISCOURSE IN VENEZUELA OF HUGO CHÁVEZ: \\ REFORM OF THE AMENDMENT TO THE CONSTITUTION (2007-2009)
}

\author{
Juan Eduardo Romero J.* \\ Yessica Quiñonez** \\ Carlos Pinto*** \\ Eduvio Ferrer****
}

\begin{abstract}
RESUMEN
En el presente trabajo, se aborda desde los enfoques de la teoría política y el análisis del discurso, la construcción del discurso político sobre la reforma constitucional propuesta por el presidente de Venezuela, Hugo Chávez en enero de 2007 y que significó la generación de un debate político sobre las implicaciones y el impacto que sobre la sociedad venezolana podría tener. Se identifican los protagonistas $y$ antagonistas políticos movilizados, sus discursos y las tramas expositivas que explican su postura de aceptación o rechazo a la propuesta de reforma. Se concluye estableciendo que el resultado fue el producto de un choque cultural en torno a las percepciones de cambio político de los venezolanos.
\end{abstract}

PALABRAS CLAVES: VENEZUELA * DISCURSO POLÍTICO * PRESIDENTE CHÁVEZ * DEMOCRACIA $*$ REFORMA CONSTITUCIONAL $*$ COMPORTAMIENTO POLÍTICO

* $\quad$ Historiador de la Universidad de Zulia. Investigador adscrito al Ministerio de Ciencia y Tecnología en Venezuela $y$ del Centro Nacional De Historia ( $\mathrm{CNH})$ adscrito al Ministerio de Cultura. juane1208@gmail.com

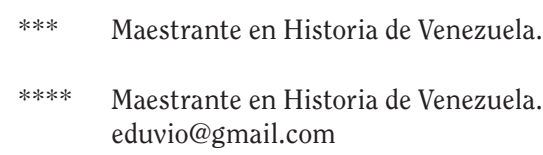

eduvio@gmail.com

** Maestrante en Ciencias de la Comunicación de la Universidad de Zulia.

yesuheyqui@hotmail.com 


\begin{abstract}
In this paper, is raised from the approaches of political theory and discourse analysis, the construction of political discourse on constitutional reform proposed by Venezuelan President Hugo Chávez in January 2007, and that meant a generation of political debate on the implications and impact which Venezuelan society could have. Identified the political protagonists and antagonists involved, their plots and expository speeches that explains his position to accept or reject the proposed reform. It concludes by stating that the result was the product of a culture shock on the perceptions of political change in Venezuela.
\end{abstract}

\title{
KEYWORDS: VENEZUELA $*$ POLITICAL DISCOURSE $*$ CHAVEZ PRESIDENT * DEMOCRACY * POLITICAL BEHAVIOUR * CONSTITUCIONAL REFORM
}

\section{ABSTRACT}

Dans ce document, est abordée dans les approches de la théorie politique et analyse du discours de la construction du discours politique sur la réforme constitutionnelle proposée par le président vénézuelien Hugo Chávez en Janvier 2007 et le fait que toute une génération de débat politique sur les implications et l'impact sur la société vénézuélienne aura. Identifie les protagonistes politiques et les antagonistes de cause, leurs parcelles de terrain et d'exposition des discours expliquant sa position d'accepter ou de rejeter la réforme proposée. Il conclut en affirmant que le résultat est le fruit d'un choc culturel sur la perception du changement politique au Venezuela.

MOTS-CLÉS: VENEZUELA * DISCOURS POLITIQUE * PRÉSIDENT CHAVEZ * DÉMOCRATIE * RÉFORME CONSTITUTIONNELLE * COMPORTEMENT POLITIQUE

\section{INTRODUCCIÓN ${ }^{1}$}

El gobierno de Hugo Chávez (1999-2008) ha experimentado diversos procesos socio-políticos. Ha pasado de una relación de convivencia con la vieja estructura política, expresada en la situación vivida entre febrero de 1999 y diciembre del mismo año, en donde sin entrar en un conflicto abierto con las fuerzas o actores políticos históricos, mantuvo una relación que se estructura en un ámbito conciliación-conflicto.

1 Este artículo es producto del trabajo que se desarrolla en el marco del Proyecto de Investigación Cambio Histórico en Venezuela, que se desarrolla con el apoyo financiero, logístico y humano de: la Universidad del Zulia, a través del CONDES y los alumnos de la Cátedra Sistema Político Venezolano e Historia de Venezuela; Fundacite-Zulia y el Centro Nacional de Historia ( $\mathrm{CNH}$ ) organismo adscrito al Ministerio del Poder Popular para la Cultura.
A partir de la aprobación de la Constitución de la República Bolivariana de Venezuela (CRBV) en diciembre de 1999, adelanta un proceso de ajuste institucional que culmina con la relegitimación de julio de 2000, que abre el ciclo de la protesta violenta $y$ no convencional que se extendió hasta la realización del denominado paro petrolero de diciembre de 2002 hasta febrero de 2003. Esa etapa, marcada por una conflictividad sin cuartel y un reto constante a la institucionalidad democrática fue progresivamente desmontada, a través de la mediación de la Organización de Estados Americanos (OEA), el PNUD y el Centro Carter.

Se dio inicio a una etapa que denominaremos paz inestable, que tiene como marco temporal las dinámicas de negociación que condujeron a la convocatoria del Referendo revocatorio de agosto de 2004, hasta la elección de diciembre de 2006, con el triunfo de Chávez sobre Manuel Rosales. Esa paz inestable, fue 
sustituida por una etapa que llamaremos de ajuste ideológico político, que se concretó en la convocatoria de una reforma constitucional para diciembre de 2007. En este trabajo se analiza la coyuntura política de la convocatoria a referendo, los discursos políticos y sus alegatos, así como el accionar de los actores y los resultados del proceso. Todo ello, desde el enfoque del Análisis Crítico del Discurso (ACD) y el apoyo de la filosofía política.

\section{LOS FUNDAMENTOS TEÓRICOS}

El análisis se basa en dos elementos teóricos básicos. Uno, referido al Análisis Crítico del Discurso (ACD) entendido como un proceso que va más allá de la simple comprensión del texto o del discurso, que lleva a "descifrar" los elementos que componen el discurso.

El segundo elemento teórico, está constituido por lo sostenido por Michel Foucault en su obra El orden del discurso (1980), que estudia los diversos factores que caracterizan un discurso. Allí habla de la capacidad implicita en un discurso para convertirse en ese instrumento de deseo que está determinada por ciertas acciones, que él denomina procedimientos de exclusión (1980:11), que deben entenderse como los mecanismos de control de la producción del discurso, y que tienen por objeto inspeccionar los acontecimientos aleatorios, conjurar los poderes $y$ peligros que expresa. Entre esos procedimientos de control, se encuentra lo prohibido, que implica que en un discurso no debe ser dicho todo, que en cualquier circunstancia no se puede hablar de cualquier cosa, transformándose en un tabú (1980:12), que regula las emisiones de ese acto social. El no decirlo todo, permite por lo tanto a quién emite el Discurso disponer de una fuente de reserva, que impide la construcción de una oposición a los deseos expresados.

Existe por otra parte, otros dos factores de regulación del discurso, son estos la razón y la locura. La Razón y la Locura, están determinados por la certeza que adquiere el Discurso, es decir, la multiplicación o no del mismo, depende no de la verdad implícita, sino de la manera cómo llega ha ser percibida por el receptor del Discurso.

Existe un tercer sistema de exclusión, considerado por Foucault: lo verdadero y lo falso (p.15-18). El primero se apoya en un sistema institucional, que viene acompañado por mecanismos arraigados en la sociedad, a través de los sistemas de edición: diarios, libros, comunicaciones, que hacen de tanto ser repetidas, que se asuman como verdaderas. La verdad, además abre las puertas a lo falso, en función del descarte.

Foucault, nos habla de otro sistema de control y delimitación del discurso: los procedimientos internos, que los entiende "como formas o principios de clasificación, de ordenación, de distribución, como si se tratase de dominar otra dimensión del discurso: aquélla de lo que acontece y del azar" (p.20-21).

Al respecto nos habla del comentario (p.22-23), como el primero de esos procedimientos internos, $y$ que permite que un relato, un discurso, un acto social del habla, pase de ser un discurso que se "dice", pero que no trasciende, no penetra la psiquis, a otros que son dichos, que adquieren por lo tanto un carácter más permanente. Conjuntamente con el comentario, Foucault nos señala otro elemento interno que es el autor (p.24-27), y lo entiende no como un simple individuo social, que emite $y$ cumple un acto cotidiano como es la expresión del habla, Foucault entiende al autor como origen y dinámica del discurso y a través del cual este adquiere significación y coherencia. Ese sentido de autor, marcha por lo tanto conjugada con el comentario haciendo trascendente un discurso, en tanto y cuanto quien lo formula tiene coherencia -0 pretende tenerla $-y$ por lo tanto sus emisiones discursivas se transforman en comentarios que son dichos.

Finalmente Foucault, nos habla de otros elementos: el ritual y la doctrina. El ritual señala ciertas características y cualidades que tienen los individuos que emiten el discurso y son esas cualidades, las que permiten definir sus gestos, su comportamiento, las circunstancias en que se producen $y$ los signos que acompañan el discurso, haciéndolo capaz de trasmitirse y multiplicarse al común de los individuos. La doctrina 
por su parte, se entiende como el reconocimiento de unas mismas verdades - o que se asumen como tales-y la aceptación de una cierta regla de conformidad con un discurso asumido como válido. Ella relaciona a los individuos con determinados grupos de expresión, de comunicación $y$ al mismo tiempo que los relaciona, los excluye de otros que no comparten esa regla, les prohíbe cualquier otra regla estableciendo sistemas de separación o de cohesión dependiendo de la situación discursiva.

Estos elementos descritos por Michel Foucault, nos sirven de marco teórico referencial para analizar el discurso de la Reforma Constitucional planteada entre septiembre $y$ diciembre de 2007.

\section{EL CONTEXTO SOCIO-POLÍTICO PREVIO A LA CONVOCATORIA DE LA REFORMA (2006)}

La profunda conflictividad social experimentada en el país en el período 2002-2005, donde las fuerzas y actores socio-políticos se sumieron en una relación puro-conflicto, caracterizada por un discurso político deshumanizador del "otro", negador de la condición ciudadana pero sobre todo basado en el desconocimiento de un espacio de diálogo, fue sucesivamente sustituido por un clima de tensión social, que sin llegar a niveles de explosividad, hizo posible retomar el cauce de la participación democrática.

El 3 de diciembre de 2006, se llevaron a cabo las elecciones presidenciales en Venezuela. La disputa estaba concentrada en las candidaturas del actual presidente Hugo Chávez Frías y la de Manuel Rosales, Gobernador del estado Zulia $^{2}$. Toda la campaña ${ }^{3}$ estuvo signada por

$2 \quad$ El estado Zulia está ubicado en la zona noroccidental de Venezuela, limita con la República de Colombia, específicamente con los departamentos de la Guajira, César y Norte de Santander. Produce más del $60 \%$ del petróleo de exportación y representa casi el $15 \%$ de la población electoral en el país. Adicionalmente es uno de los principales Estados en producción agrícola y pecuaria.

Hemos publicado un análisis sobre las condiciones de la campaña electoral en Venezuela, una dinámica discusión en torno a la construcción de procesos enmarcadores ${ }^{4}$, a través de los cuales definían su perspectiva y visión acerca de la democracia, el sistema político y la utilización de la renta petrolera.

Para Chávez, la campaña se construyó sobre el eje de una confrontación con los intereses de los EEUU en la región, sobre la idea de profundizar el "proceso revolucionario" adelantado desde su llegada al poder en diciembre de 1998, a través del mantenimiento del conjunto de Misiones que implementó sobre todo a partir de 2003.

La campaña de Rosales, estuvo marcada por las constantes críticas al uso de la renta petrolera por parte del gobierno de Chávez, haciendo hincapié en la práctica desarrollada de apoyar económicamente a otros países, utilizando para ello recursos provenientes de la bonanza petrolera.

Adicionalmente, ambos candidatos decidieron establecer una disputa por el electorado clave: los estratos D y E, que representan más del $80 \%$ de la población con derecho a voto e inscrita en el Registro Electoral Permanente (REP). Fueron meses de constante actividad y movilidad por parte de ambos candidatos, en su búsqueda de las preferencias del electorado $y$ de un gasto inmenso en publicidad electoral, buscando llegar a todos los sectores claves, tal como se desprende del siguiente cuadro, que refleja las cifras de gasto de los candidatos concurrentes a la elección de diciembre de 2006:

en nuestro blog. Pueden consultarse nuestros trabajos en <http://www.historiador-juanromero. blogspot.com $>\quad y<$ http://www.historiadorparaentenderalchavismo.blogspot.com>

$4 \quad$ Lo entendemos como un conjunto de significados compartidos y conceptos sobre los cuales los ciudadanos tienden a definir su situación y que sirven de estímulo para la acción colectiva. 
CUADRO 1

GASTO ELECTORAL POR CANDIDATO (AGOSTO-NOVIEMBRE 2006)

\begin{tabular}{lccccc}
\hline CANDIDATO & AGOSTO & SEPTIEMBRE & OCTUBRE & NOVIEMBRE & TOTAL \\
\hline Hugo Chávez & 1100300300 & 5346377000 & 8940178400 & 1628649600 & 17015505000 \\
Manuel Rosales & 1627850000 & 1918500000 & 21045000 & 2161455000 & 8558850000 \\
Angel Irigoyen & 52301503 & 0 & 0 & 0 & 52301503 \\
Jesús Cabrera Infante & 1000000 & 300000 & 16000000 & 0 & 17300000 \\
Luis Reyes & 2000000 & 1200000 & 0 & - & 3200000 \\
Lucrecia Contreras & 0 & 500000 & 1000000 & 1200000 & 2700000 \\
Alejandro Suárez & 0 & 1000000 & 200000 & 0 & 1200000 \\
Isbelia León & 979810 & 0 & 0 & 0 & 979810 \\
Homer Rodríguez & 0 & 500000 & 260000 & - & 760000 \\
Carmelo Romano & 200000 & 0 & 0 & - & 200000 \\
José Tinedo & 200000 & 0 & 0 & 0 & 200000 \\
Pedro Aranguren & 10000 & 0 & 0 & 0 & 10000 \\
\hline
\end{tabular}

Fuente: Elaboración propia a partir de datos del CNE.

\subsection{LOS TEMAS EN LA CAMPAÑA DE CHÁVEZ}

Para Chávez, la campaña se presentó como una disputa con los intereses de los EEuu Desde un comienzo el Comando Táctico Nacional (CTN) del partido Movimiento Quinta República (MVR) estableció que la línea temática para desarrollar la campaña electoral de 2006 sería una confrontación con la intención del gobierno de George W. Bush por inmiscuirse en los asuntos internos de Venezuela ${ }^{5}$. No hay duda del profundo carácter ideológico de esta propuesta. Se trataba de recurrir a una estrategia de deslegitimación y minimización del candidato opositor al reducirlo a una simple representación de los intereses de los EEUU en la región.

Comparativamente, al analizar la votación del chavismo en los dos últimos procesos electorales importantes a escala nacional (elecciones de agosto de 2004 y las presidenciales de diciembre de 2006), se observa no sólo un crecimiento de la población electoral, sino que además el

5 Puede consultarse el documento elaborado por el CTN del MVR en la siguiente dirección: <http:// www.e-lecciones.net/novedades/archivos/ Estrategia\%20de\%20Campa_a\%20de\%20Ch_vez. pdf $>$ caudal electoral del chavismo aumentó, en forma significativa, tal como se desprende del cuadro 2.

La estrategia de continuidad de la gestión política fue efectiva. El triunfo de Chávez y el manejo que realizó del impacto de las misiones demuestra cómo al ubicarse el electorado clave, y actuar en función de la satisfacción de los intereses del mismo, puede asegurarse una elección. Estudios de opinión, ya señalaban para mayojunio de 2006, que la población consultada tenía una enorme aprobación de la gestión desarrollada en las misiones (pueden consultarse el estudio de Hinterlaces de mayo, 2006. En: <http:// www.e-lecciones.net/novedades/ archivos $>$ ).

El chavismo, en el proceso de diciembre de 2006, ratificó una dinámica de transformación del sistema político venezolano, que ha pasado de un sistema multipartidista a un sistema de partido dominante ${ }^{6}$, en donde claramente resalta una fuerza política: el Movimiento Quinta República

6 Al respecto puede consultarse un trabajo que hemos publicado en la Revista de Historia Actual, que analiza los cambios en la dinámica política en Venezuela entre 2002-2004. En: <http://www. historia-actual.com/hao/Volumes/Volume1/Issue9/ esp/v1i9c4.pdf>. 


\section{CUADRO 2 \\ VOTACIÓN DEL CHAVISMO \\ ELECCIONES AGOSTO 2004 Y DICIEMBRE 2006}

\begin{tabular}{lclc}
\hline AÑO Y TIPO DE ELECCIÓN & POBLACIÓN ELECTORAL & $\begin{array}{l}\text { ABSTENCIÓN } \\
\text { ELECTORAL }\end{array}$ & $\begin{array}{l}\text { VOTACIÓN OBTENIDA POR } \\
\text { EL CHAVISMO }\end{array}$ \\
\hline $\begin{array}{l}\text { Agosto de 2004 } \\
\text { Referendo Revocatorio }\end{array}$ & 14037900 & $30,08 \%$ & 5800629 \\
$\begin{array}{l}\text { Diciembre de 2006 } \\
\text { Elección Presidencial }\end{array}$ & 16103235 & $25,94 \%$ & 7300388 \\
\hline
\end{tabular}

Fuente: Elaboración propia con base en datos tomados del Consejo Nacional Electoral.

(MVR) fundado por el propio Chávez en 1997, con 4822175 votos.

A pesar, de la dominación preponderante del MVR, el 2007 se presentó como un proceso de construcción en torno a un frente político único, que el propio Chávez ha denominado Partido Socialista Unido de Venezuela (PSUV), que pretende concentrar las fuerzas políticas gravitantes alrededor del liderazgo personal de Chávez.

Partidos como Podemos, que obtuvo 756742 votos, Patria para Todos (PPT) con 594582 o el Partido Comunista de Venezuela (PCV) que obtuvo 340499 votos en las últimas elecciones de diciembre de 2006; se ven en la disyuntiva de incorporarse a esta propuesta de Chávez, pero que de entrada señala cómo aquellos que no lo acepten quedarán fuera de las estructuras de poder, el propio Chávez afirmó: "Los partidos que quieran, manténganse, pero saldrán del gobierno. Conmigo quiero que gobierne un partido. Los votos no son de ningún partido, esos votos son de Chávez y del pueblo, no se caigan a mentiras"?

Lo paradójico de este accionar, es que el MVR se había venido consolidando cómo una fuerza política importante, y no sólo el partido de Chávez, agrupaciones como Podemos ${ }^{8}$, el

$7 \quad$ "Chávez llama a conformar el Partido Socialista. Al socialismo no vamos a llegar por arte de magia... necesitamos un partido, no una sopa de letras". Prensa Presidencial. Aporrea, Caracas, 16 de diciembre, 2006. [www.aporrea.org/ideología/ n87995.html].

8 Podemos había obtenido en las elecciones legislativas de diciembre de 2005: 19 representantes a la
MEP $^{9}$, PPT, PCV, entre otras, habían aumentado su caudal electoral en los últimos procesos comiciales, pero a pesar de ello las directrices emanadas en esta etapa del proceso parecen que derivan en una estructura monolítica conformada alrededor del liderazgo personal de Chávez.

Figuras tan importantes, como Francisco Ameliach ${ }^{10}$ —diputado a la Asamblea Nacional, miembro del CTN y máximo representante del Comando Miranda de Chávez- han expresado, en el mismo tono del presidente de la República, que aquellos disidentes de la idea del partido único tendrán que someterse o irse de las estructuras de poder nacional.

La advertencia de no tolerancia de las disidencias, produjo un fenómeno de aceptación del partido único, caracterizado por la autodisolución de buena parte de las organizaciones

Asamblea Nacional, constituyéndose —-después del MVR - en la 2da fuerza política del país.

El Movimiento Electoral del Pueblo (MEP), experimentó un resurgir político con el chavismo. Esta agrupación surgida de una división de Acción Democrática (AD) en 1967, había sufrido una progresiva pérdida de su caudal electoral desde las elecciones generales del año 1988.

10 En declaraciones al diario El Nacional, el 13 de diciembre de 2006, afirmaba que "el partido único absorberá todas las militancias de esos partidos... los indisciplinados no estarán en la directrices del partido". 
nacionales, regionales $y$ locales $^{11}$ que apoyaron a Chávez en la etapa 1998-2006. En resumidas cuentas, las elecciones del 3 de diciembre no sólo generaron la desaparición electoral de fuerzas políticas de gran tradición cómo AD, COPEI $y$ el MAS ${ }^{12}$, sino que produjo que las fuerzas políticas pro-chavistas iniciarán el camino de su disolución, en una idea que se acerca al planteamiento de bloque histórico de Antonio Gramsci.

\section{LA SITUACIÓN POLÍTICA EN VENEZUELA PREVIO A LA PROPUESTA DE REFORMA CONSTITUCIONAL (ENERO-AGOSTO 2007)}

Los resultados del triunfo de diciembre de 2006, señalaban una consolidación del caudal electoral del chavismo como fenómeno político. En ese sentido, Chávez pareció indetenible en la construcción de un bloque hegemónico capaz de aglutinar diversas fuerzas sociales movilizadas en torno a las propuestas sociales e institucionales implementadas. La oposición al chavismo lucía desdibujada y seriamente afectada por la naturaleza de la derrota electoral. Todo indicaba que las fuerzas sociales estructuradas alrededor de Chávez configurarían un sistema político de partido dominante, con una gran fuerza política constituida alrededor de la unidad propuesta desde el Partido Socialista Unido de Venezuela (PSUV). En este marco institucional de debilidad de las fuerzas de oposición a Chávez es que se planteó la aprobación de una Ley Habilitante, que le permitía formular un conjunto de Leyes sin tener que pasar por la discusión con la Asamblea Nacional.

El Nacional 22/12/2006, cuerpo A-2, anuncia que 35 grupos políticos declaraban su autodisolución y adherencia al Partido Socialista Unido de Venezuela (PSUV) sugerido por el presidente Chávez.

12 AD decidió no apoyar ni participar en las elecciones de diciembre, por su parte COPEI apenas llegó a obtener 256000 votos, el MAS no alcanzó el 1\% requerido — apenas logró 68000 votospara mantener su estatus de partido nacional, por lo cual queda prácticamente disuelto y obligado a recolectar las firmas requeridas $-20 \%$ del electorado nacional- para poder participar nuevamente en un proceso comicial.
Chávez introduce esta discusión conjuntamente con el elemento de la reingeniería del Proyecto Bolivariano ${ }^{13}$, en la propuesta de los Cinco motores del proyecto Simón Bolivar:

1. La Ley Habilitante, pensada para promulgar posiblemente un total de 65 o más leyes, directamente por parte del Ejecutivo Nacional, contando con la autorización del Poder Legislativo, representando en la AN, totalmente cercana al Presidente.

2. Educación o Moral y Luces, destinada al avance a partir de un proyecto socialista de Educación, sobre la base de una Ley Orgánica de Educación, que se encuentra paralizada desde el año 2001, una Ley de Educación Superior (PLES), todos instrumentos que deberían facilitar en la lógica del planteamiento chavista la socialización y gratuidad completa de la Educación.

3. La Reforma Constitucional, estructurada en función de ajustar algunos elementos que son considerados problemáticos en la Constitución de 1999, sobre todo relacionada con la Estructura del Poder Político y las garantías del sector económico, entre otras.

4. El Poder Popular o Comunal, cuya introducción busca favorecer los mecanismos de democracia directa, a través de las figuras de los Consejos Locales de Planificación y Los Consejos Comunales, pero que podría revestir el riesgo de una excesiva atomización del poder local, basado en el aprovechamiento de los recursos directamente asignados por el Ejecutivo Nacional.

5. La Nueva Geometría Territorial, que se basa en el planteamiento de una reordenación de la estructura espacial y territorial, tanto en lo que respecta a la población y su ubicación, como en lo atinente a la organización del poder municipal y local.

Al asumir el 10 de enero de 2007, para el período 2007-2013, Chávez comenzó una estrategia política, que a nuestro entender tiene dos líneas significativas. La primera de ellas, está asociada a la estructura organizativa de

13 Acerca del Proyecto Bolivariano consúltese nuestros trabajos en el blog <http://www.historiadorparaentenderalchavismo.blogspot.com $>$. 
las fuerzas políticas que lo apoyan. Como bien sabemos, el partido Patria para Todos (PPT), cuya cabeza más notoria, es el ex-Ministro de Educación, Aristóbulo Iztúriz, el partido Podemos, y el Partido Comunista de Venezuela (PCV), son las tres organizaciones que conjuntamente con el Movimiento Quinto República (MVR) le dan sustento a su gobierno, sin embargo todas estas organizaciones tienen un denominador común: dispersión y ambición personal.

En los diversos procesos enfrentados por el chavismo, la desorganización y la carencia de una estructura de poder que le permita construir - firmemente - la hegemonía, ha sido la nota característica. El chavismo, ha pasado por diversos intentos de organizar sus fuerzas: 1) El Comité Político Constituyente (CPC) (1998-1999) conformado por diversas personalidades, entre las que destacaron los hoy opositores Pablo Medina, Oswaldo Álvarez Paz, Hernann Escarrá, entre otros, 2) Comando Político de la Revolución (CPR) (2001-2002), 3) Comando Ayacucho (2003-2004), 4) Comando Maisanta (2004), 5) Unidades de Batalla Electoral (UBE) (2004-2006) y 6) Comando Miranda (2006). Todos ellos, pensados como un Frente Amplio que reúne a todos los integrantes del chavismo, no obstante la forma de articularse no ha resultado tan viable, ni tan deseado por el propio presidente.

Esta primera línea, desemboca en la propuesta del Partido Socialista Unido de Venezuela (PSUV), que si bien puede tener un sustento en la crisis de liderazgo y organización de todas las agrupaciones políticas pro-chavistas, la manera cómo fue decretado - a través de un anuncio amenazante del ciudadano-presidente-deja entrever profundas divisiones a futuro, ya que la nueva estructura política está pensada de una manera dominante sobre la base del culto personalista a Chávez.

La segunda línea, deriva de un pensamiento que busca acelerar una "transición" al socialismo a la venezolana — según Chávez - a través de una dinámica de reingeniería constitucional e institucional. Eso conlleva el otorgamiento de plenos poderes por parte de la Asamblea Nacional (AN), mediante una Ley Habilitante que le permita al presidente legislar sin la mediación de la AN.
Esa solicitud, debe entenderse en el contexto planteado por Chávez de una búsqueda —intensa - de la efectividad y eficiencia, al mismo tiempo debe verse cómo la preocupación del chavismo por el retardo en la promulgación de leyes en el poder legislativo, sobre todo por el papel que los legisladores de PPT y Podemos puedan tener en las discusiones parlamentarias.

Otro punto importante, es que leyes consideradas vitales para su Gobierno, como la Ley de Policía Nacional, la Ley Orgánica de las Fuerzas Armadas, deben ser aprobadas por este medio. Asimismo hay una serie de leyes pendientes - ley de Hacienda Estadal, Ley de Seguridad Social_ que piensan ser incorporadas.

Otra área de esta línea estratégica, está determinada por el reajuste territorial. Chávez habló de eliminación de la estructura de poder municipal, para darle más poder a los Consejos Comunales -organizaciones comunitarias que por ley reciben asignaciones directas de recursos para inversión y obras - pensando que los 333 municipios que componen la estructura espacial venezolana, deben mejorar su eficiencia en la distribución de los recursos económicos provistos a través de la distribución del situado constitucional.

\section{LA PROPUESTA DE REFORMA CONSTITUCIONAL}

En el contexto del triunfo contundente, expresado en un crecimiento constante de la votación o caudal electoral del chavismo ${ }^{14}$,

Lo entendemos como un movimiento social, que ha adquirido en el transcurso del tiempo un poder electoral producto de la movilización popular. Hemos señalado que preferimos hablar de chavismos, en plural ya que ese movimiento social se encuentra conformado por un conjunto de elementos diversos, en donde sobresalen cuatro secciones: 1) la militarista, inicialmente comprometida en el intento de golpe de 1992; 2) la de izquierda, en donde encontramos a viejos militantes de la izquierda histórica; 3) los movimientos sociales y culturales, que reivindicaron durante mucho tiempo su derecho a resistirse a la dominación de los partidos AD y COPEI y 4) los tránsfugas, que vienen de los viejos partidos del statu quo y que se anotan con la nueva fuerza política. 
entre el año 2000 hasta el 2006, el presidente Chávez realizó una lectura política basada en esos resultados. La elevación del número de votos efectivos aunado a otras determinantes tales como el control en la mayoría de las gobernaciones hacía ver plausible avanzar hacia el definitivo desplazamiento de la oposición política. El chavismo había pasado de obtener más de 3500000 votos cuando ganó el presidente las elecciones de 1998, a más de 7000000 de votos en diciembre de 2006, tal como se desprende del siguiente gráfico:

GRÁFICO 1

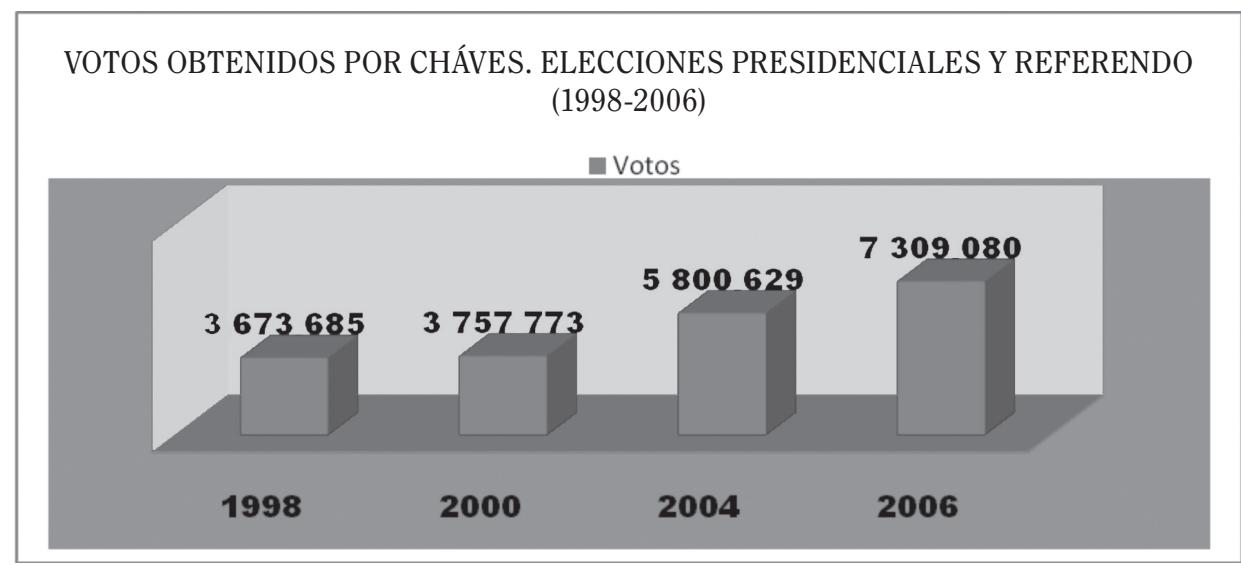

Fuente: Datos del Consejo Nacional Electoral. Elaboración propia. 2008.

Ese aumento del apoyo popular, aunado al desplazamiento y minimización de los oponentes al proyecto bolivariano, fueron lo que llevaron a Chávez a anunciar la reforma constitucional $y$ sus ejes estructurantes, como una vía para la construcción de lo que se ha llamado el Socialismo del Siglo XXI15. Esa dinámica política pareció posible dada la magnitud del triunfo sobre Manuel Rosales como candidato único de la oposición. En esas circunstancias pareció ser la oportunidad politica ${ }^{16}$ adecuada para la concreción de su hegemonía política y la conformación de un bloque histórico en el sentido gramsciano del término. Por ello su afirmación en el denominado "Balcón del Pueblo"17 en

15 Chávez afirmó: "el socialismo que estamos construyendo no está reñido con la democracia". Discurso 15 de diciembre de 2006.

Sidney Tarrow (1999:89) la define como “... señales continuas percibidas por los agentes sociales o políticos que les animan o desaniman a utilizar los recursos con los que cuentan para crear movimientos sociales".

Se denomina así una estructura ubicada en el Palacio de Gobierno que da a una de las calles más
Miraflores la misma noche del 2 de diciembre de 2006, cuando se conocieron los resultados de la consulta electoral: "La nueva época que hoy comienza tiene como línea estratégica fundamental la profundización, la ampliación y la expansión de la revolución bolivariana, de la democracia revolucionaria en la vía venezolana hacia el socialismo" (El Nacional, 04/12/2006).

Ese camino al Socialismo debió consolidarse a través de un conjunto de instrumentos jurídicos que abarcarán diversos aspectos considerados claves para el ajuste institucional del Estado y el modelo de sociedad misma. Para el chavismo, se trató de activar a los movimientos sociales que lo apoyaban para generar una acción colectiva que no sólo derivará en el ajuste institucional buscado, sino que además se tradujera en el definitivo desplazamiento de las estructuras de poder de las fuerzas políticas que se le oponían. El cálculo político no pareció errado. Los resultados electorales así lo demostraban y permitió suponer lo oportuno de una

concurridas de Caracas, $y$ desde donde el presidente Chávez se dirige a sus seguidores cada vez que hay un gran anuncio político que hacer. 
estrategia final que condujera a la victoria definitiva sobre quienes se han opuesto al proyecto Bolivariano desde 1998.

Se trataba no sólo de un resultado político ventajoso para el chavismo, sino que también las encuestadoras daban como cierto la popularidad y el apoyo al presidente, tal como lo indicaba la encuestadora Datanálisis en un reportaje del diario El Nacional (31/12/2006, $\mathrm{A}-5)^{18}$. Ese apoyo y popularidad era otro elemento sobre el cual se construyó el discurso político de la Reforma.

Chávez, convirtió el tema de la Reforma Constitucional en un discurso que es dicho, es decir, en un discurso que por aceptación o rechazo es repetido constantemente. Al dar el paso inicial de solicitar la Reforma, tomó una delantera importante en la conformación de un discurso político que sirviera como marco de referencia ${ }^{19}$ a través del cual se generó la movilización colectiva. Esos marcos de referencias fueron elementos discursivos sobre los que los actores conformaron su actuación como protagonistas $^{20}$ o antagonistas $^{21}$, ante una audiencia que debían convencer y que en la lectura del chavismo, ya lo estaba, tal como pareció indicarlo los resultados de la elección de diciembre de 2006. Se trataba de darle continuidad a un marco de referencia que - según el criterio de Chávez - había sido planteado en la escogencia

Señalaba que cerca del $71,9 \%$ de la población encuestada percibía positivamente la gestión del presidente Hugo Chávez y de ellos un $52,8 \%$ se declaraba chavista.

19 Hunt, Benford y Snow (2001:222) lo definen como “... un esquema interpretativo que simplifica $y$ condensa el "mundo exterior" al señalar y codificar selectivamente los objetos, situaciones, acontecimientos, experiencias y las acciones que se han producido en el entorno presente o pasado de cada individuo".

20 Se define como "un tipo de individuos y de colectivos que son identificados por su forma de promover o simpatizar con los valores o metas y prácticas de un movimientos social" (Ídem).

21 Son un conjunto de personas que parecen unidos para oponerse a los esfuerzos de los protagonistas (Ídem). política donde resultó favorecido ante la opción representada por Manuel Rosales. No obstante, para el chavismo resultó en una lectura errónea de la realidad electoral; aunque insistimos, la realidad del momento pareció concederle la razón. Esta apreciación había sido esbozada por el Consultor de opinión pública de Datanálisis en una entrevista aparecida en El Nacional el 31/12/2006, donde advirtió que el chavismo no podía tomar al pie de la letra el apoyo electoral dado, pues había en su composición un sector "duro" y otro que se adhiere convenientemente al ganador ${ }^{22}$.

Ese debate, siguiendo a Foucault fue ubicado por el chavismo como un elemento de razón, es decir, como una estructura discursiva lógica, con sentido y peso basado en los resultados electorales y sobre el cual debía avanzarse hacia el Socialismo del Siglo XXI, que se asumió como un camino a recorrer por los venezolanos. Sobre esa base, Chávez se convirtió en un protagonista en la construcción de un marco de referencia que teniendo al "Socialismo a la venezolana" se comenzó a debatir.

En ese proceso comenzaron a aparecer los antagonistas a su propuesta, esgrimiendo razones sobre las cuales se oponían a la propuesta de Reforma y que buscaban resistirse a la misma. Uno de esos antagonistas, y que por su vinculación pasada con el chavismo adquirió más peso mediático fue el Dr. Hermann Escarrá23 quién estableció elementos discursivos que serían fundamentales

Decía José Antonio Gil Yepes: "La primera conclusión es que todos los chavistas y más de la mitad de los independientes votaron por la reelección del Presidente. Si desagregamos más esas cifras, nos encontramos con que sólo $22 \%$ de los venezolanos, un tercio de quienes votaron por Chávez, son chavistas "patria o muerte": personas con una alta carga emocional, dispuestas a todo por seguir al Presidente y totalmente satisfechos con su gestión. Las otras dos terceras partes están asociadas a lo que llamamos un "chavismo utilitario": personas que critican la gestión de gobierno, pero al final terminan votando por Chávez porque tienen una relación directa con el estado; becas, empleo en una dependencia del Gobierno, contratos con empresas del Estado o beneficios de las misiones" (31/12/2006: A-4).

23 Ex miembro de la Asamblea Nacional Constituyente en 1999. Abogado Constitucionalista, profesor 
a la resistencia civil a la propuesta del presidente, entre los que cabe señalar: 1) su carácter contrario al marco conceptual establecido en la Constitución de la República Bolivariana de Venezuela (CRBV) y 2) lo equívoco de la propuesta del socialismo del siglo XXI como contrario a los intereses y la idiosincrasia del venezolano ${ }^{24}$.

Quedaron progresivamente plasmados los términos conceptuales o marcos de referencia sobre el cual se generaría el enfrentamiento entre Chávez, sus Ministros, Legisladores y movimientos sociales como protagonistas y los partidos de oposición, Iglesia, Medios de Comunicación y otros movimientos sociales como antagonistas. Para el Chavismo, se trataba de presentar una propuesta que era lógica bajo el marco referencial expresado en los comicios nacionales celebrados en diciembre de 2006 y que debían conducir a una profundización del ajuste institucional iniciado en 1999. Para la oposición, se trataba de una "locura" del chavismo que conducía irremediablemente a un "choque cultural" con el sentido e identidad del venezolano, que en su particular percepción rechazaría el socialismo del siglo XXI.

Al definir cada sector político — el protagónico y el antagónico- sus marcos referenciales, se adelantó la expresión de las razones que motivarían o impulsarían la acción colectiva de las audiencias que serían claves en el triunfo o

universitario y uno de los co-redactores principales de la CRBV de 1999. Fue una figura principal en la estructura inicial del gobierno de Chávez entre 1999-2001. Llegó a ocupar un cargo como Magistrado del Tribunal Supremo de Justicia. Posteriormente se desprendió del chavismo y pasó a oponérsele insistentemente.

24 Escarrá afirmaba en una entrevista aparecida en $E l$ Nacional lo siguiente: "Se modifican la estructura $y$ los principios fundamentales del texto constitucional mediante un fraude al poder constituyente originario del pueblo", denunció. "Además, el contenido de la propuesta presidencial es extremadamente grave al pretender sustituir la fórmula política de la Constitución vigente, la de un Estado democrático y social de derecho y de justicia, la del Estado federal descentralizado y la del gobierno democrático participativo, alternativo y pluralista, por el inefable socialismo del siglo XXI". (El Nacional 09/10/2007, A-3). rechazo de cada una de las propuestas. Para ello, cada sector acudió a los actores que adelantarían la defensa de sus respectivos marcos referenciales. Se debe recordar que según Foucault, a través de los actores, el discurso adquiere significación y trascendencia. Cada actor, según su papel de protagonista o antagonista, impulsaba la presentación de la propuesta de reforma como un acto de razón o un acto de locura. Esa asignación de referentes permite la aceptación o el rechazo de sus planteamientos. Cuando se asume como un acto de razón, puede ser reproducido y multiplicado por cada uno de los actores, en caso de señalarse como un acto de locura, se produce una deslegitimación de los planteamientos.

Para el chavismo, se trataba de un acto razonable, pensado en el marco de la acción de gobierno y el proyecto bolivariano esbozado en el Plan de Desarrollo Económico y Social de la Nación (PDESN) 2001-2007 y en el PDESN 20072013, conocido también como Plan Simón Bolívar. Los autores que se pronunciaron compartieron una doctrina común: que la reforma constitucional generaría beneficios y consolidaría el camino hacia el socialismo del siglo XXI. Ese marco de referencia fue expresado por Alejandro Uzcategui, Presidente de EMPREVEN ${ }^{25}$. Quién señaló:

-Y ese ha sido el gran éxito del presidente Chávez (el socialismo y nacionalismo petrolero). No te imaginas la cantidad de empresarios socialistas que hay en Venezuela.

—Me quedo asombrado. Yo dije en Aló, Presidente que respaldábamos el socialismo y recibí 46 mensajes de los empresarios míos: Así es, doctor, defienda el socialismo, lo felicitamos. Es increíble (El Nacional 26/08/2007 N-6).

25 Abogado y comerciante ligado a poderosos grupos económicos cercanos al gobierno de Hugo Chávez. Fundó y dirige una Asociación Civil que se denomina Empresarios por Venezuela (EMPREVEN), que es el equivalente de la central patronal FEDECAMARAS y que normalmente se presenta antagónica con esta. Es un apoyo financiero importante en el gobierno de Chávez. 
Cuando se habla de defensa al socialismo, se establece con ello que es lógico seguir en el avance político logrado o alcanzado en el período 1999-2006. Se identificaban de esa manera las necesidades de adecuar la Constitución al parecer ideológico — que según sus lecturashabía sido expresado en diciembre de 2006. No hay que perder de vista, que este ajuste socio-político vino acompañado por la propuesta de lanzamiento del Partido Socialista Unido de Venezuela (PSUV) como una instancia instrumental para la aplicación y ejecución del Socialismo del Siglo XxI.

La apreciación que con el triunfo de diciembre de 2006 se entraba a una etapa definitiva en la implementación del proyecto bolivariano, no era únicamente de los adeptos o seguidores del presidente; sectores tan disímiles y lejanos como la Iglesia Católica lo percibían igualmente. Para algunos miembros de la Conferencia Episcopal de Venezuela (CEV) como Baltazar Porras ${ }^{26}$, no había duda de ello:

A partir de las elecciones de diciembre último se ha acelerado el proceso revolucionario, donde la intransigencia y la aplanadora del gobierno se están haciendo sentir. Hay un secuestro de todos los poderes públicos por parte del Ejecutivo. No existe sino un único poder (El Nacional 29/07/2007 I-9).

Para Porras, como para buena parte de los antagonistas a Chávez y su propuesta de reforma, la misma conducía irremediablemente hacia el socialismo, pero no según el modelo venezolano planteado por el presidente, sino hacia uno que emulaba -o podía emular- los errores del comunismo soviético, cubano o chino ${ }^{27}$.

26 Es arzobispo de la Ciudad de Mérida, en el occidente de Venezuela, uno de los estados más importantes por su aporte económico y su posición de cercanía con la frontera colombiana. Secretario General de la CEV y consecuentemente enfrentado con el gobierno de Hugo Chávez. Ha sido denunciado por el gobierno como muy cercano a la oposición política por su presencia en Fuerte Tiuna en abril de 2002, durante la entrega de Chávez a los militares rebeldes.

El propio Monseñor Porras afirmaba en la entrevista "Caminamos hacia eso (El socialismo del siglo $\mathrm{XXI})$. Lo ha dicho públicamente, que el ejemplo es
Ese planteamiento era parte de la doctrina que fue usada por la oposición política a Chávez para crear un marco de referencia, que facilitara la construcción de articulaciones o significados que fueran considerados por la sociedad como agresivos contra la identidad misma del venezolano. Esa estrategia corresponde con lo que algunos teóricos (Hunt et ál., 2001:228) han denominado marcos de diagnóstico, entendido como situaciones problemáticas y necesitadas de cambio, de la cual son responsables ciertos agentes sociales. La importancia de los marcos de diagnósticos - como un tipo de marco de referencia sobre el cual se construyen opiniones públicas - es que conducen al establecimiento de marcos de pronóstico, que son acciones que impulsan la actividad colectiva para solucionar las "injusticias" denunciadas y dan paso a marcos generadores de motivación (Hunt et ál., 2001:229); que son aquellos que justifican la construcción de un vocabulario de motivos adecuados para movilizarse a favor de una causa.

Cuando Chávez anunció, que la reforma daría paso al Socialismo del Siglo XXI, creó las condiciones para que existiera una movilización cultural, entendida como una activación de la participación colectiva para oponerse a una reforma política que fue considerada atentatoria de las características culturales del venezolano. No creemos que la reforma condujera a un socialismo al estilo soviético o cubano, pero sí creemos que la Doctrina estructurada por los antagonistas, permitió que el ciudadano creyera que sí era posible y se movilizara para impedirlo. La propaganda política, estimuló ese marco de referencia y construyó sus argumentos sobre esa percepción.

A nuestro entender, el chavismo falló en la construcción de un campo de identidad de los protagonistas que permitiera llevar adelante procesos de alineamiento mediante los cuales se difunden $y$ defienden los significados enunciados a través del discurso político. Para los protagonistas asociados al presidente Chávez,

Cuba (...). Hay la permanente repetición de cómo la sociedad, hacia la cual debemos caminar, es la cubana o es la de Corea del Norte, o es Irán; en fin, sus modelos a seguir y a imitar son modelos muy cuestionados en la sociedad mundial hoy en día" (El Nacional, 29/07/2007). 
los campos de identidad se basaban en ciertos planteamientos doctrinarios: 1) la necesidad de adecuar la CRBV a los cambios ideológicos impulsados por la revolución bolivariana; 2) la ampliación del poder popular y de la democracia radical o participativa y 3) la ampliación de la cobertura del Estado de Bienestar en el área social.

Para la oposición a Chávez, que actuaba como antagonista a su propuesta, el campo de identidad era entendido como un alineamiento de opiniones que asignaban responsabilidad $y$ culpabilidad sobre una situación particular. En el caso del discurso político se trataba de una serie de elementos doctrinarios: 1) no era necesaria una reforma constitucional para avanzar en la profundización de ciertos aspectos sociales y económicos propuestos; 2) la reforma constitucional contravenía los valores democráticos de la sociedad venezolana y 3) Chávez era culpable de intentar perpetuarse en el poder. Ambos campos de identidad se dilucidaron ante los medios de comunicación, ese proceso ocurre cuando marcos interpretativos chocan fuertemente entre sí y se generan enfrentamientos que son reflejados a través de la opinión pública, que se da a la tarea de reproducir constantemente los referentes sobre los cuales se estructuran las opiniones de cada grupo.

Cabe preguntarse ¿qué produce esos enfrentamientos que se expresan en los medios de comunicación? La respuesta la da uno de los teóricos más importantes Mayer Zald, quién señala que "las oportunidades políticas y de movilización son el resultado de un proceso de rupturas culturales que hacen aflorar a la superficie contradicciones que habían estado allí, latentes, desde hacía tiempo" (1999:378).

En el caso venezolano, la transición política y los cambios culturales que impulsaron el cambio político a finales del siglo $\mathrm{xx}$, hicieron aflorar las contradicciones existentes en cuanto a la participación política de los ciudadanos en el sistema de gobierno establecido desde 1958. La implementación de determinadas fórmulas institucionales en el funcionamiento del sistema político desde 1999, generó un enfrentamiento entre la idea de democracia radical o participativa, sostenida por el chavismo y la idea de democracia representativa, sostenida por quienes se oponen al chavismo ${ }^{28}$. Dichos planteamientos políticos en torno a representaciones de la democracia disímiles, son en sí mismas, una gran contradicción ${ }^{29}$, que se ve especialmente reseñada por la prensa venezolana. Esa reseña alcanzó un punto máximo durante la campaña por la Reforma Constitucional entre agosto y diciembre de 2007.

Algunos connotados autores de los antagonistas a Chávez, reforzaron las apreciaciones o marcos de referencia, que insistían en lo inapropiado de las acciones políticas planteadas por el Presidente de la República. Tal es el caso de una Carta Abierta de Profesores, Decanos e Investigadores de Derecho Constitucional de diversas universidades del país, que señalaron en octubre lo siguiente:

La definición del Estado y de la democracia como socialista pone en grave riesgo el pluralismo y la convivencia democrática, más aún cuando los medios de participación política se encuentran condicionados a la construcción del socialismo (El Nacional, 31/10/2007. N-4).

En la misma tónica de crear un marco que critique la reforma, pero adicionando la interpretación que la reforma era ilegal y violentaba el estado de derecho vigente en la CRBV

Un trabajo interesante que refleja los cambios que en las áreas política, económica, social, se generaron con la aprobación de la CRBV es el coordinado por Salamanca y Viciano (2004). Puede consultarse el texto El fenómeno Chávez (Ramos, 2003), así como los trabajos de Romero (1999, 2000 , 2001, 2002, 2003, 2004) en donde se abordan los cambios sociales y culturales en las percepciones políticas de los venezolanos.

29 Chávez incentivó aun más esas contradicciones cuando habló en su discurso del 15 de diciembre de 2006 de las características del socialismo "la transformación del modelo económico es fundamental sí queremos construir un verdadero socialismo. Entonces, hay que socializar la economía, el modelo productivo...". Estas afirmaciones causarían revuelo durante la campaña, pues fueron entendidas en asociación con el modelo socialista soviético que se basó en la expropiación y la concentración en manos del Estado de buena parte del sector productivo. 
se encuentra una declaración del Foro Penal Venezolano:

Hemos dicho públicamente, y lo seguimos manteniendo, que los mecanismos que se están utilizando para la reforma del texto constitucional son en sí mismos inconstitucionales $y$ violatorios de derechos humanos $y$ fundamentales que reposan en el pueblo como portador del poder originario. Es así que las decisiones que se han tomado desde la Presidencia de la República, convalidadas por la comisión presidencial nombrada para los efectos de reforma constitucional, $y$ hasta ahora avaladas por la Asamblea Nacional son, en estricto derecho, irritan y atentan contra los postulados fundamentales de rango constitucional sobre los que no le está dado al poder proponer modificación alguna. Se violan los mecanismos de cambios constitucionales establecidos por la misma Carta Magna (Foro Penal, 14/10/2007).

La Iglesia Católica, otro sector activamente antagonista a la reforma, afirmaba - afianzando el marco de referencia que planteaba un contraste en los campos de identidad de democracia vs. socialismo- que la propuesta de Chávez conducía a un retroceso en la democracia sobre la cual habían sido formados los venezolanos ${ }^{30}$.

Uno de los más importantes autores representantes, que señalaba lo perjudicial que era la reforma constitucional en la búsqueda del socialismo, con los valores de los venezolanos y latinoamericanos en general, fue el

30 En un documento denominado Llamados a vivir en libertad señalaban: "En este modelo socialista propuesto, el Estado y el gobierno estarían dirigidos por un presidente que puede ser reelecto continuamente, con un poder amplísimo que le permitiría disponer de las instituciones, propiedades y recursos. Un modelo de Estado socialista, marxista, leninista, estatista es contrario al pensamiento del Libertador Simón Bolívar y también es contrario a la naturaleza personal del ser humano $y$ a la visión cristiana del hombre porque establece el dominio absoluto del Estado sobre la persona" (CEV, 28/10/2007 reseñado por El Nacional).
Cardenal Jorge Urosa ${ }^{31}$, quién es presidente de la Conferencia Episcopal Venezolana (CEV). El cardenal fue contundente en algunas declaraciones al indicar que el socialismo estaba distante de la naturaleza y sentido de la sociedad liberal, que limitaba la participación social y contravenía las formas de vida republicana; con ello estableció una contundente posición en contra de la Reforma adelantada por Chávez, empleando para ello el uso de referentes culturales que fueron plasmados de forma tal que se evidenciara la contradicción de valores.

No hay duda de la línea de continuidad en torno a los argumentos presentados por quienes se oponían a la reforma constitucional. Esa oposición se articuló sobre los mismos elementos: inconveniencia constitucional, marcado carácter socialista contrario a la naturaleza política de los venezolanos, manifestación de la ambición de Chávez por perpetuarse en el poder. Los argumentos se repetían una $y$ otra vez por parte de los antagonistas - autores los llamaría Michel Foucaultque daban declaraciones ante los medios de comunicación. Un caso emblemático fue el de Yon Goicochea ${ }^{32}$, estudiante del 5to. año de Derecho en la Universidad Católica Andrés Bello (UCAB) y Secretario General del Parlamento de la Juventud y los estudiantes, que daba unas declaraciones donde ratificaba los argumentos en contra de la reforma:

31 Llegó a plantear en una entrevista reproducida por el diario El Nacional de fecha 31/12/2007 lo siguiente: "Otra razón por la cual el socialismo marxista no funciona es porque no reconoce la grandeza de la persona humana, sino que le da la primacía y hegemonía al Estado, lo cual se reduce después al puñito de personas que componen el gobierno que son los iluminados, los que lo saben todo, los que han encontrado la luz y que van a guiar al pueblo, a pesar de que el pueblo no quiera por los caminos que unilateralmente decidieron" (P-2).

32 Entre mayo y julio de 2007, en el marco del cese de la señal abierta del canal de televisión Radio Caracas Televisión (RCTV), se generó una reacción de resistencia a la medida por parte del movimiento estudiantil en diversas ciudades del país. El foco de inicio fue el movimiento estudiantil de la UCAB en donde Yon Goicochea surgió como un referente, constituyéndose en una figura que reiteradamente apareció en los medios de comunicación. 
Nuestro papel es ayudar a la gente a entender el fondo de esta reforma. Que limita la pluralidad política, al imponer un Estado socialista y la reelección indefinida; que violenta las libertades económicas; que afecta el derecho al sufragio; que limita el derecho a la información y al debido proceso en estados de excepción; entre otras cosas. Este es un debate de ideas, y estamos dispuestos a ir a cualquier parte. Pero lo dejamos muy claro: nuestros interlocutores no son los estudiantes oficialistas. Nosotros queremos confrontar con los representantes del poder (El Nacional, 28/10/2007, N/4).

No hay duda, que las expresiones usadas por Goicochea, como representante del movimiento estudiantil, buscan consolidar una argumentación destinada a procurar el desarrollo de un conjunto de razones que justifiquen la movilización en apoyo a la causa motivadora. Goicochea lo tiene muy claro cuando inicia la declaración señalando que "nuestro papel es ayudar a la gente a entender el fondo de esta reforma", y para ello utilizó los argumentos que sirvieron de campo de identidad para todo aquel opuesto a ella, ampliando de forma tal que se transformará en un marco generador de motivación, sobre la idea de la contrariedad cultural de la propuesta con las identidades políticas del venezolano.
La expresión de esta disputa se concretó en el proceso de elecciones del 2 de diciembre de 2007. En ese momento se demostró cual de los marcos interpretativos, expresados por protagonistas $y$ antagonistas tuvo mayor efecto. Sin duda, los resultados hablan por sí mismos: el chavismo se vio seriamente perjudicado por el efecto mediático de la discusión acerca de la reforma. No logró desmontar las matrices de opinión tejidas desde las Doctrinas sostenidas por los grupos y movimientos políticos opuestos a él, y por el contrario la votación misma de Chávez se vio seriamente afectada, sobre todo si se toman en consideración los parámetros de votos obtenidos en el 2006 por estados y su correspondiente votación en el 2007.

Sin duda, los resultados del referendo para reformar la CRBV no fueron positivos para el chavismo y abrió el escenario para la confrontación política al ponerle fecha de término al período presidencial de Hugo Chávez. Por otra parte señaló que la estrategia de "construcción del socialismo" no ha sido bien percibida por los adeptos o simpatizantes del chavismo, que se abstuvieron de manifestar su apoyo a la propuesta del presidente y con ello, generan una derrota mínima pero simbólicamente importante para el denominado Proyecto Bolivariano.

GRÁFICO 2

RELACIÓN ENTRE LA VOTACIÓN DE CHÁVEZ EN EL 2006 Y 2007

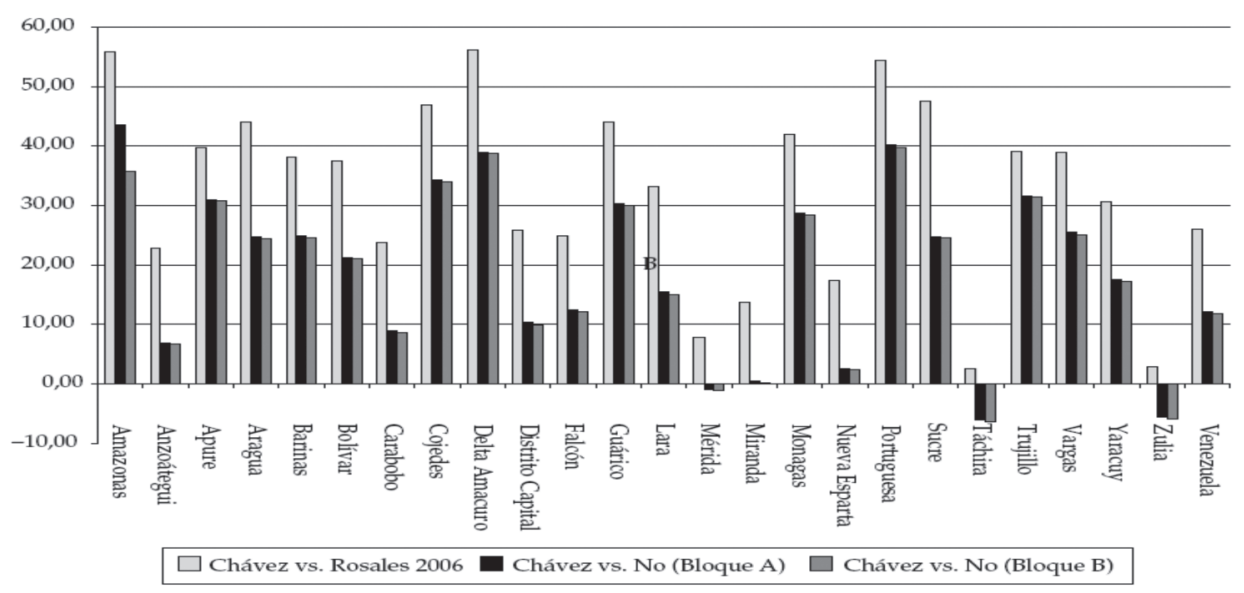

Fuente: Álvarez, Ángel (2008). 


\section{LA ESTRATEGIA POLÍTICA DE CHÁVEZ: ¿POPULISMO O NEOPOPULISMO?}

El diseño de la política, la manera en que es asumida la acción pública y la forma de articulación con los colectivos sociales ha generado un debate significativo en torno a la tipificación del gobierno de Hugo Chávez como populista ${ }^{33}$, sí bien otros lo enmarcan dentro del concepto de neopopulismo ${ }^{34}$.

Como bien es sabido, el contexto político-histórico de aparición del populismo se ubica entre las décadas de 1920-1960 cuando se establece un sistema de sustitución de importaciones al mismo tiempo que se impulsa la incorporación como sujetos políticos de los trabajadores y obreros. Los trabajos de Germani y De Tella (1973) y Octavio Ianni (1975) fueron clásicos en sus caracterizaciones basadas en cuatro (4) aspectos: la imagen del líder, las particularidades de su discurso, el momento histórico en que nace el movimiento y su política económica. En torno a la imagen del líder, no hay duda que Chávez encaja en la tipificación de carismático, pero revestido de un manejo profundo de elementos históricos (Romero, 2005) que le dan un sustento cultural sobre la base del proceso histórico venezolano. El manejo de la idea del árbol de las tres (3) raíces - Simón Bolívar, Simón Rodríguez y Ezequiel Zamora- es una estrategia de contextualización del proyecto político formulado por el propio Chávez

Consúltese los trabajo de Arenas $(2005,2007)$ y Koeneke (2003) donde se señalan algunos aspectos que según los autores ubica a Chávez en el entorno populista.

Al respecto el trabajo publicado en la web por Juan Pedro Denaday (2005) presenta al gobierno de Chávez en una postura neopopulista, dado el carácter de su política económica y de movilización social. En: <http://www.corrientepraxis. org.ar/spip.php?article28>. En esta misma línea, pero con un trabajo conceptual más sólido hay que reseñar al politólogo José Antonio Rivas Leone (2002) donde resalta las características de su discurso movilizador y la relación que tiene con la crisis del SPV. También a Márquez Restrepo (2000) donde se ahonda en precisiones teóricas y análisis de la realidad venezolana. y que resalta la importancia de la contextualización histórica.

En lo que respecta a las particularidades del discurso, hemos señalado en otros estudios (Romero 2001, 2006) que el discurso de Chávez es un discurso en constante transmutación, que maneja referentes históricos que tradicionalmente habían sido limitados en el proceso venezolano, que es activamente movilizador al estar conformado sobre la idea de la democracia radical de la cual habla Ernesto Laclau (2006).

Por otra parte, para hablar del momento histórico en el cual surge Chávez hay que entender el profundo deterioro del sistema político venezolano (SPV) en el lapso 1983-1998, cuando se desmonta todo el aparato político y se produce una pérdida de legitimidad de los actores institucionales del sistema (López, 2004; Molina y Álvarez, 2004), aspecto que facilitó el propio ascenso de Chávez al poder (Ramos, 2003). El último aspecto, la política económica tiene diversos momentos. En el caso de Chávez, no podemos hablar de una política económica esencialmente nacionalista $y$ antiimperialista en el período 1999-2002; por el contrario en esa etapa se produce una convivencia de recíproca conveniencia entre el capital económico - nacional y trasnacional- con el aparato político del gobierno.

Será posterior al intento de golpe de estado de abril de 2002, cuando se genera un furioso enfrentamiento de Chávez, principalmente con el capital norteamericano y sus intereses económicos en el país. En ese proceso se va dibujando una fuerte política nacionalista que propende a la estatización y control por parte del Estado venezolano de los factores ligados al capital, principalmente en lo que respecta a áreas estratégicas: hidrocarburos, siderúrgica, metalúrgica, agricultura, ganadería, entre otros ${ }^{35}$.

Todo ello enmarcado en el denominado Proyecto Simón Bolivar, que impulsando el Poder Comunal ha propiciado la organización descentralizada desde "abajo" de una estructura productiva que pretende surgir

Actualmente el Estado ha nacionalizado y retomado el control de la Compañía de Teléfonos (CANTV), de PDVSA, SIDOR (Siderúrgica del Orinoco), así como de algunas fábricas ligadas a la industria alimenticia (leche $y$ otros rubros). 
como alternativa al gran capital, que tradicionalmente ha controlado el aparato económico en Venezuela (Ellner, 2006).

El resultado ha devenido en un enfrentamiento de las fuerzas políticas del chavismo - a través de la organización del PSUV y sus aliados - tanto con el capital nacional como extranjero, así como con los actores políticos $y$ sociales producto del ajuste institucional del Proyecto Bolivariano dibujado a partir del triunfo del año 2006. La iniciativa de Reforma Constitucional del 2007, tal como lo hemos señalado, pretendió acelerar la transición al modelo socialista pensado $y$ anunciado reiteradamente por el propio Chávez, su derrota fue sólo parcial, tal como lo demuestra la iniciativa que retomó a partir de los resultados políticos de las elecciones regionales de noviembre de 2008 , cuando el chavismo recuperó espacios en el denominado corredor electoral - conformado por las entidades federales más importantes electoralmente hablando - llegando a alcanzar el control de un número importante de gobernaciones y alcaldías (Ver Gráficos 3 y 4).

GRÁFICO 3

ALCALDÍAS (GOBIERNO Y OPOSICIÓN) 2004-2008

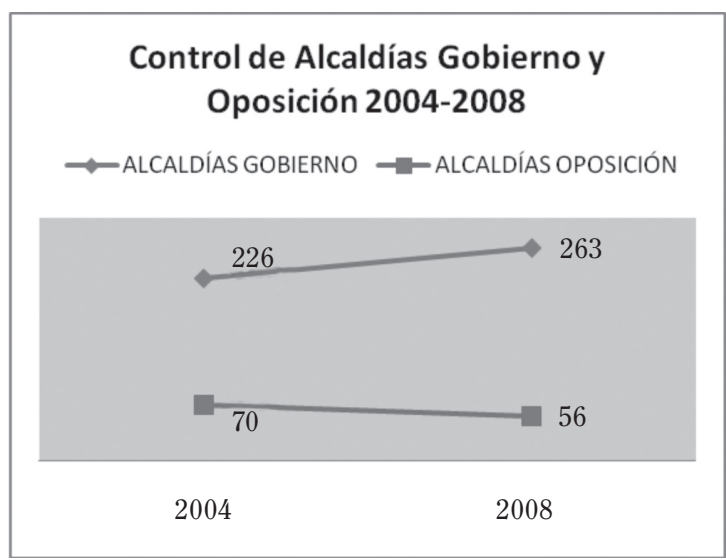

Fuente: Consejo Nacional Electoral, elaboración propia.

GRÁFICO 4

GOBERNACIONES POR PARTIDOS (2004-2008)

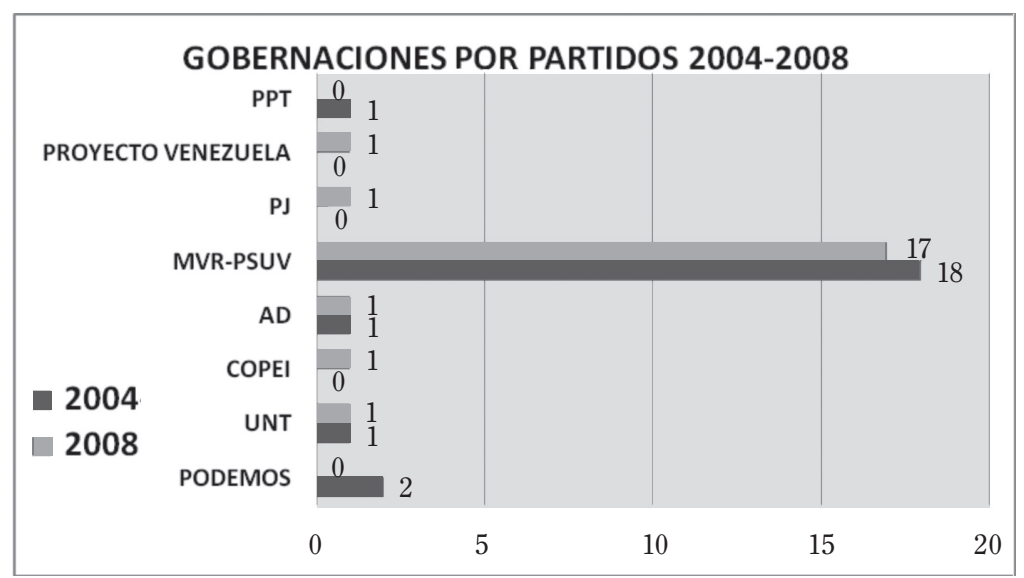

Fuente: CNE, elaboración propia. 
Esa recuperación del caudal electoral de las fuerzas políticas del PSUV, fueron factor esencial en el lanzamiento de la propuesta de una Enmienda Constitucional de la CRBV, en lo referente a los Art. 230, 160, 162, 174 y 192, todos referidos a la eliminación de las restricciones para poder postularse a quienes ejercen un cargo público (Presidencia de la República, Gobernadores, Alcaldes, Legisladores Nacionales y Regionales). Como es sabido, la CRBV estableció limitaciones a la postulación, permitiéndoles a las autoridades antes nombradas ser elegidos únicamente por una segunda vez. Con la propuesta de Enmienda, Chávez solucionaba el problema de la sucesión presidencial, pues tal como lo explicamos, al ser derrotada la Reforma del 2007, se generaba un debate hacia lo interno del PSUV para definir al "sucesor" del presidente en el liderazgo político $y$ en la aspiración al control del poder ejecutivo.

Esa discusión fue sustancialmente eliminada cuando con base en los resultados electorales de noviembre de 2008 el chavismo recuperaba parte de su fuerza política y en una estrategia de lucha sin descanso - aplicando sin duda la lógica militar al campo político-se lanzó en un nuevo proceso electoral que encontró sin recursos y perplejos a los partidos, grupos y personalidades políticas que se le habían opuesto — con éxito- en el 2007.

Las fuerzas opuestas al chavismo, pretendieron de nuevo construir una Doctrina basada en los siguientes elementos: 1) la Enmienda era inconstitucional, pues la propuesta de modificación del Art.230 ya había sido rechazada, 2) Chávez pretendía con la Enmienda perpetuarse en el poder, 3) la Enmienda violentaba el principio constitucional de Alternabilidad.

Por su parte, las fuerzas aglutinadas en torno al PSUV y el Comando Simón Bolívar ${ }^{36}$ lanzaron una estrategia estructurada en torno a la defensa de los logros sociales de la Revolución

El choque político no sólo fue en torno a la propuesta de la Enmienda, también se manifestó en la denominación de los Comandos a favor del sí $y$ por el NO. Los que apoyaban la propuesta del presidente se agruparon bajo la denominación simbólica de Simón Bolívar y los del NO, bajo la denominación Comando Angostura, representando con eso una posición histórica emblemática,
Bolivariana y el costo que significaría perder la oportunidad de reelegir a Chávez, para darle continuidad al Proyecto Bolivariano por un período más allá del 2013, cuando legalmente se le vence el período que inició con el triunfo en las elecciones presidenciales del 2006. De tal forma, que la Doctrina de las fuerzas en pugna estaba de nuevo siendo definida a través de un conjunto de frames ${ }^{37}$, que eran esbozados a través de los medios de comunicación social.

De nuevo se definieron el conjunto de antagonistas y protagonistas, según fuera la defensa del NO o el sí. Entre los antagonistas surgieron un conjunto de profesores universitarios de Derecho Constitucional en universidades públicas y privadas $^{38}$, quienes emitieron un Comunicado de fecha 16/12/2008 en donde hacían críticas al carácter jurídico de la convocatoria a una Enmienda que había adelantado la Asamblea Nacional.

En términos parecidos, un conjunto de representantes estudiantiles, entre los que cabe citar al Presidente de la Federación de Centros Universitarios (FCU) de la Universidad Central de Venezuela (UCV) Ricardo Sánchez, así como los Presidentes de la FCU de las Universidades Privadas Monte Ávila y la Simón Bolívar (USB) ${ }^{39}$,

que traslució dos (2) formas de entender la historia y la política.

37 Según Sadaba (2004: 69) son entendidos como "patrones persistentes de cognición, interpretación y presentación de la selección, énfasis y exclusión, a través de los cuales quiénes manejan los símbolos organizan de forma rutinaria el discurso".

Bajo el título de Comunicado de Profesores de Derecho ante la Enmienda Constitucional (En: <http://www.globovision.com/news. php?nid=106304>), se planteaba la ilegitimidad de la consulta por violar el principio de alternabilidad y por producirse la negación de la propuesta en la consulta del 2007. La Doctrina se repetía coherentemente en este comunicado de docentes de derecho constitucional y con ello, se hacía extensiva la base comunicativa o el frames que sería empleado para intentar rechazar la Enmienda.

39 Documento consignado al CNE por parte del Movimiento Estudiantil en fecha 23/01/2009. Puede consultarse la versión electrónica en: <http://www. globovision.com/news.php?nid=1085 68>. 
entregaron en la sede del CNE una comunicación donde llamaban la atención al ente gubernamental sobre supuestas violaciones al principio de alternabilidad, pero al mismo tiempo agregaban lo que consideraban una alteración de los principios democráticos al no darse un lapso mayor para que las partes presentarán sus alegatos a favor o en contra de la Enmienda. Sin duda alguna, la estrategia que les había funcionado a los antagonistas a Chávez en 2007 estaba siendo utilizada o repetida en una coyuntura diferente.

Ante ello, hay que señalar como la aplicación de la estrategia militar a la política por parte del presidente $y$ el PSUV introdujo diversos cambios, que en nuestro entender fueron claves para explicar el triunfo del sí sobre el NO, en la consulta por la Enmienda celebrada el 15 de febrero de 2009. En ler. lugar, el estilo de la propaganda política usada por las fuerzas del chavismo hizo especial hincapié en la preservación de los logros sociales alcanzados por el gobierno en el lapso 1998-2009. En 2do. lugar, en esta oportunidad el gobierno utilizó las bases jurídicas de convocatoria a un proceso de Enmienda, contenido en el Título IX de la CRBV, que establece que la consulta se debía realizar un (1) mes después de ser consignada ante el CNE. En este sentido, los representantes de la Asamblea Nacional —en donde el PSUV es mayoría- entregó la propuesta al CNE el 14 de enero, con lo cual quedó fijada la celebración de las elecciones para el 15 de febrero. Con ello, los protagonistas de la Enmienda no cometían el error de permitirle — tal como pasó en el 2007- a la oposición un lapso de tiempo relativamente largo para tejer una estrategia comunicativa para lograr movilizar a los ciudadanos en torno a la idea de rechazar la Enmienda.

En este sentido, la lucha se trasladó a los medios de comunicación, desatándose un conflicto que osciló entre baja y alta intensidad, donde tanto los antagonistas como los protagonistas usaron los aliados que tenían en la estructura de medios públicos como privados. Lógicamente, que se produjo un desequilibrio que se caracterizó por un desbalance notorio: en los medios públicos, sobre todo el canal del Estado - Venezolana de Televisión (VTV) - la propaganda por el sí fue mayoritaria, pero en los medios privados la hegemonía de la propaganda por el No fue también notoria, tal como se desprende del siguiente estudio ${ }^{40}$ :

\section{GRÁFICO 5}

COBERTURA MEDIÁTICA. VENEVISIÓN ES EL ÚNICO CANAL DE TELEVISIÓN QUE MANTIENE UN EQUILIBRIO INFORMATIVO EN SUS SEGMENTOS DE ENTREVISTAS. EL BLOQUE DEL "NO" MANTIENE UNA PREFERENCIA MEDIÁTICA EN LAS TELEVISORAS Y EMISORAS PRIVADAS

TEMA ENMIENDA CONSTITUCIONAL: entrevistas realizadas por los canales de TV y Unión Radio Noticias por Bloque (Sí-No). del 19 al 23 de enero de 2009

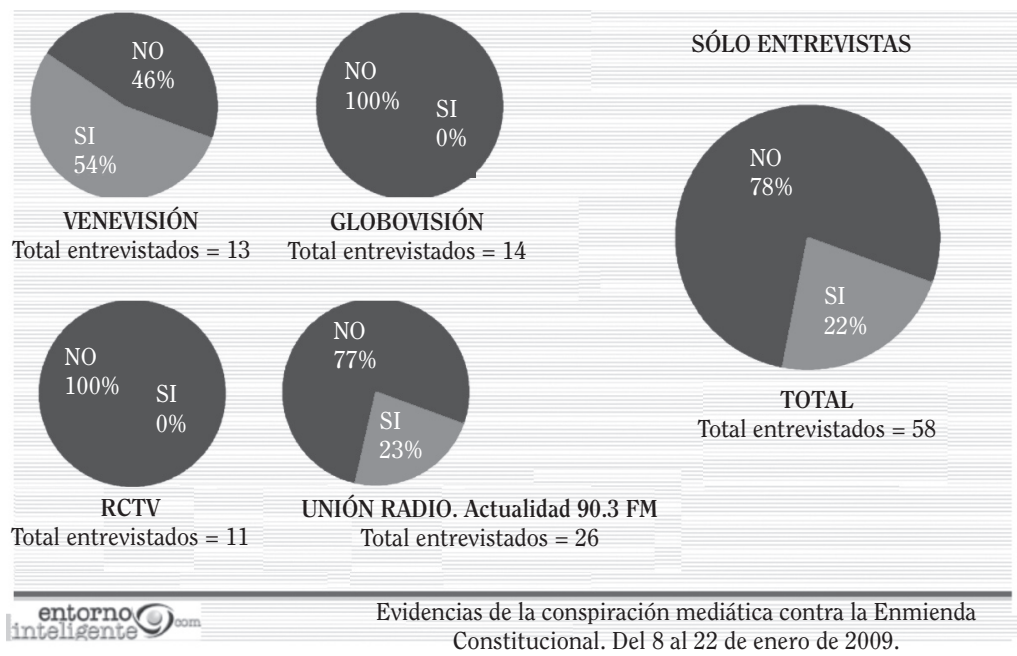

40 Los gráficos han sido tomados de la web del Ministerio del Poder Popular para la Comunicación

y la Información (MINCI), de un estudio titulado Estudio de Cobertura mediática. 


\section{GRÁFICO 6 \\ COBERTURA DE LOS BLOQUES POR EL "SI" Y EL "NO" \\ EN MEDIOS IMPRESOS TAMAÑO ESTÁNDAR}

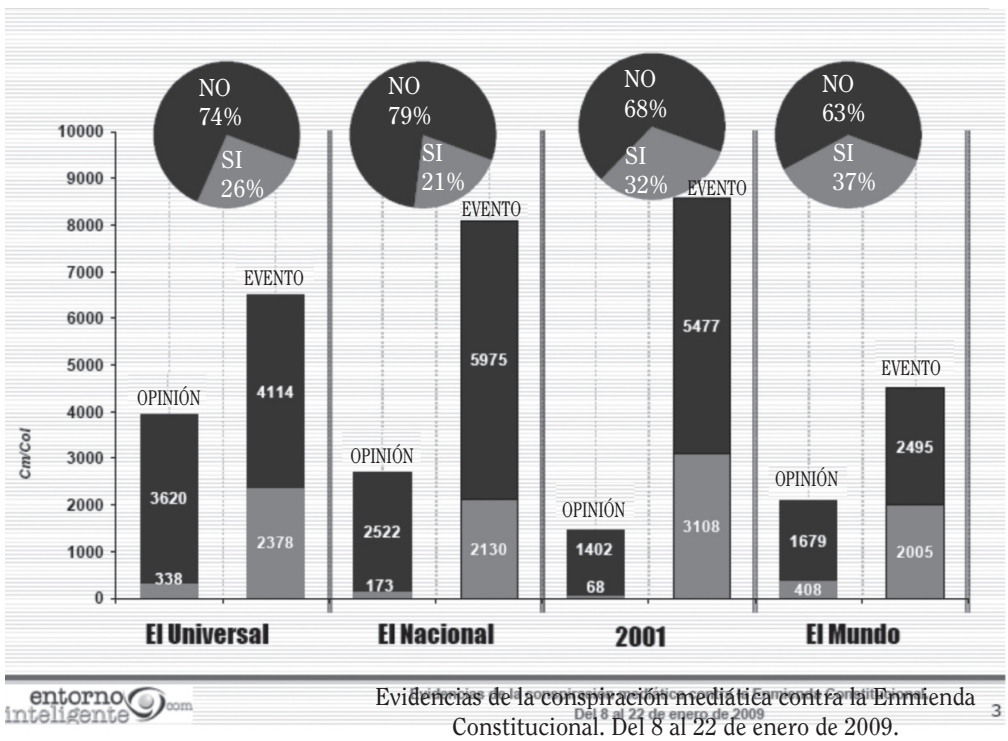

La naturaleza de la confrontación política, sobre todo en lo referente al futuro político de los factores en pugna, permitió observar cómo se produjo un ajuste socio-político por parte de los sectores polarizados en Venezuela. Para Chávez y el PSUV, el proceso electoral del 15 de febrero se tradujo en la aprobación de un ajuste constitucional que le facilita volverse a presentar como candidato en el 2013, al mismo tiempo los resultados le permitieron generar una recuperación en comparación con la votación que había alcanzado en la consulta del 2007. Es decir, pasó de obtener un promedio de 4300000 votos en la opción A y la opción B de la consulta de 2007, a lograr 6310482 votos en el 2009 (Datos CNE). Numéricamente significó una recuperación de un poco más de 2 millones de votos, no obstante sigue sin lograr aglutinar a cerca de 1 millón de votantes que se manifestaron a su favor en las elecciones presidenciales de 2006.

Por su parte, la oposición a Chávez, si bien salió derrotada en este proceso, en parte por la pretensión de mantener intacta su estrategia del 2007, pero también por la escasa capacidad de convencimiento del electorado producto de una campaña política que dijo poco; logró superar la barrera de los 4 millones de sufragios, que mantuvo desde las elecciones de 2006.

El hecho que la oposición alcanzara 5193839 (CNE) señala no un deterioro de la supremacía política de Chávez, pero sin duda sí constituye un aviso acerca de la propia capacidad del Proyecto Bolivariano para afrontar los problemas de inseguridad, empleo, burocratismo, corrupción y desarrollo económico. Ya han surgido quienes han hecho un llamado a construir un diálogo productivo.

Estos resultados parecen avizorar cambios en la conformación y correlación de fuerzas en el SPV, sin duda habrá que esperar las consultas venideras que se celebrarán en el país, durante este año 2009 y el 2010, cuando se re-legitiman los concejales y miembros de la Asamblea Nacional, pero mientras tanto no hay duda que el chavismo sigue siendo la fuerza hegemónica en el país. 
BIBLIOGRAFÍA

Álvarez, Ángel. "Venezuela: ¿la revolución pierde su encanto?". Revista de Ciencia Política 28 (1). Chile. 2008.

Arenas, Nelly. "El gobierno de Hugo Chávez: populismo de otrora y de ahora". Revista Nueva Sociedad 200. Caracas, Venezuela. 2005.

Arenas, Nelly. "Poder reconcentrado: el populismo autoritario de Hugo Chávez". Revista Politeia 30 (39). Caracas: Instituto de Estudios Políticos, Universidad Central de Venezuela (UCV), 2007.

Denaday, Juan P. "Ascenso de masas $y$ neopopulismo en Venezuela". Corriente Práxis. 2005. En: <http:// www.corrientepraxis.org.ar/spip. php?article28>.

Ellner, Steve. "Las estrategias desde arriba y desde abajo del movimiento de Hugo Chávez". Cuadernos del CENDES 23 (062). Caracas: UCV, mayo-agosto 2006.

Foucault, Michel. El orden del discurso. Barcelona: Editorial Plaza \& James, 1980.

Germani, Gino y De Tella, Torcuato. Populismo y contradicciones de clase en América Latina. México: Ediciones Era, 1973.

Hunt, Scott; Benford, R. y Snow, David. "Marcos de acción colectiva y campos de identidad en la construcción social de los movimientos". Laraña, E. y Gusfield, J. (Eds). Los nuevos movimientos sociales. De la ideología a la identidad. España. Ediciones del Centro de Investigaciones Sociológicas (CIS), 2001: 222.

Ianni, Octavio. La formación del Estado Populista en América Latina. México: Ediciones Era, 1975.
Laclau, Ernesto. "Por qué construir el pueblo es la tarea principal de la política radical”. Cuadernos del CENDES 23 (062). Caracas: ucv, mayo-agosto 2006.

López Maya, M. "Venezuela 2001-2004: actores y estrategias". Cuadernos del CENDES 21 (056). Caracas: ucv, mayo-agosto 2004.

Márquez R., Martha. "El neopopulismo en Venezuela”. Revista Papel Político 11. Colombia. 2000.

Molina, José y Álvarez, Ángel. Los partidos políticos venezolanos en el siglo XXI. Caracas: Vadell Hermanos Editores, 2004.

Ramos Jiménez, Alfredo. La transición venezolana. Aproximación al fenómeno Chávez. Mérida: Ediciones del Centro de Estudios Políticos de la ULA, 2003.

Rivas Leone, José A. "Neopopulismo y antipolítica en Venezuela". Venezuela Analitica. 2002. En: <http:// www.analitica.com/va/politica/ opinion/7347122.asp>

Romero, J. et ál. "Relaciones entre el poder civil y militar en Latinoamérica: el caso de Venezuela (1958-1999)". Revista Historia de América 124. México. Instituto Panamericano de Geografía e Historia, enero-junio 1999a: 21-45.

Romero, J. et ál. "Actores políticos y construcción del discurso del poder en Venezuela (1996-1999)". Martínez Ruiz, Enrique (Coord.). Poder y mentalidades en España e Iberoamérica. MadridEspaña: Universidad Complutense de Madrid, 2000.

Romero, Juan. "El discurso político de Hugo Chávez (1996-1999)”. Revista Espacio Abierto 10 (2). Venezuela: La Universidad del Zulia, abril-junio 2001. 
En: <http://redalyc.uaemex.mx/redalyc/ pdf/122/12210204.pdf $>$.

Romero, Juan. "Discurso y filosofía política en Hugo Chávez (1996-1998)". Revista Ecuador Debate 55. Ecuador. Abril 2002a. En: <http://www.lahora.com.ec/ debate/paginas/debate489.htm>.

Romero, Juan. "Construcción política del disenso y el conflicto a partir de las elecciones de 2000 en Venezuela". Revista Espacio Abierto 12 (1). Enero-marzo 2003a: 41-69.

Romero, Juan. "Hugo Chávez y la representación de la historia de Venezuela". Revista Reflexión Politica 11. Colombia. Junio 2004b: 146-163.

Romero, Juan. "Usos e interpretaciones de la historia de Venezuela en el pensamiento de Hugo Chávez". Revista Venezolana de Economía y Ciencias Sociales 2. Universidad Central de Venezuela (ucv), 2005. En: <http://www.scielo.org.ve/ scielo.php?pid=S13156411200500020001 $0 \&$ script=sci_arttext $>$.

Salamanca, Luis y Viciano, R. (Coord.). El Sistema Politico en la Constitución Bolivariana de Venezuela. Caracas. Vadell Hermanos Editores, Instituto de Estudios Políticos UCV y Fundación Centro de Estudios Políticos y Sociales, 2004: 69 .
Sadaba, Teresa. "Enfoques periodísticos y marcos de interpretación política. Una aproximación a la teoría del encuadre". Revista Política y Sociedad 41 (1). 2004: 65-76.

Tarrow, Sidney. "Estado y oportunidades: la estructura política de los movimientos sociales". McAdam, Dough; McCarthy, John y Zald, Mayer (Eds.). Movimientos Sociales: perspectivas comparadas. Madrid-España. Ediciones Istmo, 1999: 71-100.

\section{FUENTES HEMEROGRÁFICAS}

Edición Electrónica Diario El Nacional (Diversas ediciones).

\section{DOCUMENTOS EN LÍNEA}

Comunicado de Profesores de Derecho ante Enmienda Constitucional (16/12/2008). Documento electrónico publicado en: $<$ http://www.globovision.com/news. php?nid=106304>.

Documento consignado ante el CNE por parte del Movimiento Estudiantil (23/01/2009). Documento electrónico publicado en: $<$ http://www.globovision.com/news. php?nid=108568>.

Estudio de Cobertura Mediática de la Enmienda Constitucional. MINcI. Febrero 2009. En: <http://www.minci.gob.ve/ documentos/9/>. 